\title{
Teaching and Learning Communication Process as Community-based Transdisciplinary Inquiry
}

\author{
Helen Hambly Odame \& Natalie Oram ${ }^{1}$
}

\begin{abstract}
This article discusses experiences in teaching and learning communication processes oriented towards social change and development, specifically, using the approach known as community service learning (CSL). The relevance of CSL is that it mobilizes university students as communicators and seeks to develop global consciousness through transdisciplinary inquiry with local communities. Using the case of an undergraduate course at the University of Guelph (Canada) involving 33 CSL individual and team projects, this article reinforces the importance of experiential learning for teaching and learning communication process. In light of policy-level calls for the reform of higher education to meet social change and development needs, CSL provides an interesting opportunity, but it also encounters distinct challenges within our academic institutions and for those of us who teach and mentor university students.
\end{abstract}

Keywords: communication, experiential learning, higher education, social justice, community development

\section{Introduction}

This article considers what it means to be a university teacher seeking to mobilize communication globally by enabling students to engage in praxis-rich, transdisciplinary inquiry within local communities. In this context, community is defined as any formal or informal organization that has developed its own identity and power through the creation of shared values, norms and goals. A learning process in which students are engaged with local communities enables all participants to reflect and act on a local development issue or problem. A process whereby university students are engaged to learn with local communities is a relatively recent educational model in Canada. The approach has become known as Community Service Learning (CSL) and has synonyms such as 'service learning' and recently, 'engaged learning' (Hayes \& King 2006).

To begin with, this article presents an overview of the CSL model and its conceptual links to 'experiential learning,' an adult learning approach popularized by David Kolb (1970; 1980). Advocates of CSL often connect their work to critical views of how higher education has a tendency towards 'banking education' a term coined by Paulo Freire in the 1970s to describe authoritarianism within educational structures and process. By way of generalization the apparent dominant model in university education works 
against students learning about the world within their own local situations. Teachers can teach global communication issues, but due to a number of challenges which we will discuss here, may find it hard to use higher education to mobilize globally within local projects. This article describes an effort to bring the CSL approach together with a communication for change and development worldview which seeks to ensure that teaching and learning is more engaged with social issues and participatory processes. This was not an easy path, but one that was worthwhile to attempt. Those of us who teach can find facilitation of social change incompatible with the available time, uncertainties or risks and current epistemological debates within higher education. Efforts in CSL may rarely be acknowledged within our institutions, and sometimes resisted by students and administration. In this article we reckon with CSL for mobilizing communication globally through local community-based learning, and encourage other scholars, teachers and students to participate in an ongoing dialogue about these issues.

\section{Mobilizing Communication Globally through Local CSL}

In today's world, the field of communication as it applies to mobilizing globally on issues of change and development exists because the future of any community, region or nation rests on processes that involve learning, networking and creating innovations - both technical and institutional. At all levels of society, complex socio-cultural, economic, political and environmental changes implicate largely invisible flows of information and communication. New media and information technologies such as wireless and Web 2.0 have made some communication processes more obvious. We are, for example, more aware of the sheer volume of interpersonal messaging that we use each day with social media. We may also be more attuned to our lack of competent communication when our emotions overtake us in everyday relational interactions (Trenholm et al 2010).

What can be less apparent is how individuals are taking the responsibility to become more active as 'glocal' citizens or communicators who make a link between their lifeworld and the lives of others within and beyond their communities (Hemer \& Tufte 2005). The starting point for thinking about communication globally while acting locally is that no matter where in the world development activity happens, local individuals and communities are the main actors of social change, and therefore, processes should be focused on their own thinking, needs and actions. ${ }^{2}$ This local actor perspective makes it especially important to explore ways in which universities can help their students (from any discipline) learn about communication for change and development by enabling them to be global citizens within their local communities. In other words, how can the university student be a collaborative learner who is accredited by communicating and working within communities?

Using communication process to rethink education to challenge both teachers' and learners' values and norms was advocated by Paulo Freire in his efforts on adult literacy and social change in northeastern Brazil in the 1960s and 1970s. Freire argued for a rejection of marked tendency to approach teaching and community development as diffusing or extending information and disguising it as 'knowledge'. Most often 'banking education' positioned individuals as empty and in need of knowledge deposits made by those in authority over the learning process. Freire's countered 'banking education' with the notion of 'liberation education' which involves participatory, dialogical com- 
munication for awareness building ('conscientization') and uses critical thinking and reflection on social situations as tools.

People are because they are in a situation ... reflection upon situationality is re-

flection about the very condition of existence; critical thinking by means of which people discover each other to be "in a situation. (Freire 2007, p. 109)

For Freire, reflection about one's situation feeds an ongoing process of dialogical communication and learning. Similarly, communication scholar Pasquali (1963) stated that the essence of dialogue in communication is based on a symmetric relational scheme, with parity of conditions between sender and receiver, and the possibility of one hearing or giving ear to the other, as a mutual will to understand one another. More often than not, such dialogue is missing in educational contexts. Teaching reinforces authoritarian social structure filling students with information. Reflection and application as essential steps for turning information into knowledge are lacking. Freire's work informs educators that non-participatory communication and learning are neither desirable nor inevitable. How then can post-secondary teachers engage in 'conscientization' and develop ways to share the ownership of learning processes with students and communities?

Over the past 40 years, important changes in both teaching and learning processes have occurred to support the notion that the learner has central importance in the teaching/learning interaction (Vella 2002). What the teacher does is less important to learning than what the learner does. Teachers are called upon to facilitate a learner-centered process. Kolb defined such a process as a learning cycle and stressed the importance of ensuring action and reflection in learning (Kolb \& Fry 1975; Kolb 1984). Experiential learning is participatory by design. Kolb recognized that learners, especially adults, want to "know where they are going" at all times and therefore structured approaches that enable students to reflect upon their learning, to understand their own learning processes, to apply what they have learned and thus allow them to become more confident and autonomous are needed. This model, referred to as 'experiential learning' fits well with approaches to teaching communication that emphasize processes focused on actors' own thinking, needs and actions.

For university students a participatory, experiential approach is relevant for moving beyond the preoccupation with "filling up" on information as opposed to experiencing opportunities for conceptualization, attitudinal development, and self-reflection that draw on their accrued knowledge, the knowledge of others and an awareness of social structures that can influence the balance of power within knowledge systems. ${ }^{3}$ The experiential learning cycle is acknowledged to be especially relevant for students who recognize the impact of their own behaviour within real life situations rather than only reading and working on their hypothetical actions in controlled classroom settings (Vella 2002). The experiential model therefore helps people assume responsibility for their own learning because it requires students to reflect on their experience, analyze and draw conclusions, and subsequently identify direction for future application.

\section{Challenges for Community Service Learning}

Worldwide, the need for students to be engaged learners who question and redevelop their knowledge, attitudes and skills within real world situations is an important policy 
emphasis for higher education. UNESCO's 2009 Communiqué on Higher Education states that education "must not only give solid skills for the present and future world but must also contribute to the education of ethical citizens committed to the construction of peace, the defense of human rights and the values of democracy." Brown et al (2010) argue that it is precisely the lack of transdisciplinary learning, network building and innovations which are undermining the development of changes in society that can address longstanding planetary dilemmas including peace, human rights and democratic processes of development. In our opinion, there are several obvious challenges to the contemporary public university experience, at least based on our experience in Canada and internationally, that implicate teaching and learning along a human rights-oriented and democracy-building trajectory. Firstly, within public education systems, students (and parents) are experiencing reduced accessibility and affordability of post-secondary education. Students are under pressure to "get in and get out" - moving through their undergraduate education as soon as possible into the workforce. Admittedly, some of these students will return to graduate level education, but this is not an option for all, again due to affordability and accessibility.

Worldwide, educational systems have to graduate competent students, and simultaneously, democratize the university and wider society (UNESCO 2009). The sustainability of public universities is precarious precisely at a time in history when demand for higher education is at its peak, due in part to global demographics that reflect the growing number of youth seeking education and economic opportunities. Faculty and university administrators are concerned with declining investment in the quality of educational process due to public sector budgetary constraints. Sufficient resources to enable universities to engage students beyond the walls of the formal classroom within community level learning processes are not allocated. Other pressures within the system also counteract the public good, democratic philosophy underlying community service learning opportunities. This can include stretching the faculty to student ratio by raising student intake but hiring no or only few contractually limited teachers (Newson \& Poulster 2010).

Community Service Learning (CSL) operates amidst these challenges in higher education by combining the goals of developing student competence and enabling social justice through community based learning (Fenwick 2000; CACSL 2011). An emphasis on capacity development for both students and community organizations implies that the teacher is more of a mentor and less of an instructor. In this respect, the teacher can only facilitate reciprocal processes of communication between students and members of the community. However, he or she can also encourage students to question hierarchies of knowledge and become more conscious of their own personal and discipline-specific assumptions about local development and the relationship between local and global change.

Typically, a CSL learning process invites students to document their experiences and build their individual self-awareness, autonomy and creativity. The analysis of one's "self" and interactions with others is an intrinsic concept within communication processes whether they take place in a private (e.g. intimate or family relationship) or public (e.g. workplace) setting (Trenholm et al 2010). Students involved in CSL may come from any academic discipline. We believe that it is ideal within the CSL learning context to involve students who come from different disciplinary backgrounds (e.g. anthropology, 
engineering, business, geography, political science, agricultural sciences, etc.) within the same course in order to develop discussion about disciplinary influences on ways of knowing and acting within the community. Using tools such as reflective learning journals and on-line discussion boards, students can identify opportunities for transdisciplinary inquiry that engage learners in questioning established ways of knowing and doing (theory and practice). Let us now turn to how these ideas were realized by using CSL to teach communication process at the University of Guelph in Ontario, Canada. ${ }^{4}$

\section{Setting CSL in Motion}

The course "Teaching and Learning in Non-Formal Education" was offered for several semesters in a classroom setting. ${ }^{5}$ When the first author of this article joined the University of Guelph in 2003, she taught this third year undergraduate class 'face to face' and approached it with some trepidation because of a deeply felt concern that an understanding of non-formal education could not be grasped within a formal educational setting. After the first offering of the course, the course was redeveloped to include a community service learning approach that would take students out of the classroom and into action-oriented learning projects within our local communities in Guelph and Wellington County. By 2008, this course had moved from an in-class course to a distance education course, offered entirely on-line within the newly established undergraduate Distance Education Certificate in Communication Process.

The city of Guelph is located in Wellington County in the heartland of the Great Lakes area of southwestern Ontario. Guelph is a university town that continues to grow rapidly due to its $100 \mathrm{~km}$ proximity to Toronto, Canada's largest metropolitan area. The rural areas and many small towns within Wellington County make the city of Guelph an important center for community-based public services that range from formal nongovernmental organizations to informal community groups or specific neighborhood activities. These few hundred not-for-profit organizations focus their attention on issues related to health, environmental sustainability, civic engagement and a wide range of support for vulnerable social groups such as children, the elderly, immigrants, at-risk youth, the unemployed, or mentally, emotionally or physically challenged persons. ${ }^{6}$

By 2006, a CSL approach was integrated into the course with some degree of confidence that students were applying the theory and practice of non-formal education within community-based projects that demonstrated collaborative learning, mutual knowledge development, shared leadership and dialogical communication. The course structure was fairly straightforward. Students were reading and discussing in class Paulo Freire's text, Pedagogy of the Oppressed in class, and completing the balance of most of their coursework in the community. Using weekly journals, they were requested to observe and reflect on their concrete experiences within the community, conceptualize and generalize their findings identifying new information emerging from within their situations, and then re-focus their engagement and actions within the community. To make the interaction with the community tangible, students and each community organization developed together a 'learning contract' that outlined their collaboration. The only requirements were to collaborate with a local community organization, and use participatory communication methods that we studied in class to identify a focus for their non-formal learning. Typically, these interactions led to framing a learning process 
and materials on a topic prioritized by members of the community. By the end of the course, these "projects" were documented descriptions of the participatory process (in the reflective journal) and materials associated with the students' community service learning experiences.

The second author of this article was a student in the course. Merging our experiences as instructor and student we decided to conduct a meta-analysis of the CSL experiences and projects that were carried out over the four year period. In total, there were 76 non-formal learning and communication process projects completed in 2005-2009. With distance education students potentially located across the province, the country or even, internationally, the context of "community-based learning" also shifted away from the Guelph/Wellington area only. Students' local communities were wherever they were living as distance learners. However, despite the on-line nature of the course about two-thirds of the students in the course were still located near to the university campus, and therefore, most often involved with organizations in or near the City of Guelph.

\section{Learning Experiences}

We randomly selected 33 CSL projects for meta-analysis with approximately half of the projects completed by individuals and half by small teams of two to three students. The projects included 21 initiatives within the local Guelph or Wellington County area and 12 projects outside of Guelph, including two elsewhere in Canada. ${ }^{7}$

The analysis looked for descriptive patterns and trends in the CSL including the content addressed in the projects, the balance of individual roles and team efforts within collaborative learning processes and evidence of critical thinking and students' global awareness through local communicative actions. Table 1 presents a summary of the CSL projects and descriptors of the social change and local development issues addressed by either individual or small teams of students.

Table 1. Community Service Learning Projects

Title of Project / Community Organization

(by location and alphabetical order)

\section{GUELPH / WELLINGTON COUNTY}

AIDS Committee of Guelph/Wellington -Harm Reduction and Safety for Injection Drug Users

Camp Joshua - Leadership for Counsellors in Training

City of Guelph Aquatics Program

*Evergreen Seniors Centre Guelph - Food, Nutrition and Agriculture Program

*Guelph Centre for Organizational Research Dealing with Difficult People

*Guelph Speed River CleanUp - Ontario Public Research Interest Group

*Junior Farmers and 4-H Ontario - Agricultural Education adults/ youth at risk; emergency communication; social stigma and change

youth leadership/voice through sports

youth; sports leadership

seniors; food and nutrition; health

interpersonal communication and anti-violence in the workplace; learning; leadership/voice environmental activism

youth (rural youth); food and nutrition; career development 
Title of Project / Community Organization (by location and alphabetical order)

\section{Topic / Descriptors}

\section{GUELPH / WELLINGTON COUNTY}

*Shelldale Community Center - Teen Drop-In Program

Station Road Nursery School, Wellington County -Fundraising and Special Events for Coop Day Care

*St. Joseph's Health Centre, Guelph - Communicating through Art

*St. Josephs Health Center - Women's Knitting Workshops

St. Joseph's Secondary School, Guelph - Special Education Program

*University of Guelph - Campus Childcare and

Learning Centre (CCLC) - Bullying Awareness

Pre-School Program

University of Guelph Campus Crusade for Christ

*University of Guelph Food Bank - Promotion and Awareness

*Weight Watchers Activity Series

Wellington Centre for Continuing Education

- Science for Home Schooling Parents and Children

Wellington Food Bank - United Way - Food and Nutrition Project

YWCA/YMCA Guelph - Anti-Bullying Program

YWCA/YMCA Guelph - Teenage Parents

Program

*YWCA Guelph - Girl Talk

\section{COMMUNITIES OUTSIDE GUELPH/WELLINGTON}

Dalhousie Citizens Coalition to Save the Mill (Dalhousie, New Brunswick)

Downsview High School - Positive Peer Culture (Greater Toronto Area, Ontario)

Engineers Without Borders (Waterloo, Ontario)

Englofun (Quebec City, Quebec)

Football for Parents (Georgetown, Ontario)

*Frontier College Migrant Worker Literacy Program (Toronto, Ontario)

*Habitat for Humanity - Volunteer Relations and Construction Committee (Brantford, Ontario)

*High School 101 - St. Brigid Catholic School (Georgetown, Ontario)

Ingersoll Seniors Activity Centre - Food and Nutrition Project (Ingersoll, Ontario) youth leadership/voice; literacy; cross-cultural communication; English as a second language cooperative workplace; organizational learning

adults and youth (mentally and physically challenged); visual arts communication

women's solidarity; leisure; leadership/voice

youth (emotionally and physically challenged); leadership/voice

children; anti-violence; leadership/voice

social change and spirituality

food security (for students)

health, food and nutrition

alternative education

social change; food security; food \& nutrition

anti-violence; leadership/voice

youth; health; leadership/voice

youth (girls) leadership/voice; health; food and nutrition

organizational learning; leadership/voice; social change

youth; leadership/voice

organizational learning; international development

cross-cultural communication; English as a second language; music for learning language

leadership through sports

cross-cultural communication; English as a second language; migrant agricultural workers; literacy; social change

homelessness; organizational learning

youth leadership/voice; career development

seniors food \& nutrition; local food sovereignty 


\begin{tabular}{|c|c|}
\hline $\begin{array}{l}\text { Title of Project / Community Organization } \\
\text { (by location and alphabetical order) }\end{array}$ & Topic / Descriptors \\
\hline \multicolumn{2}{|c|}{ COMMUNITIES OUTSIDE GUELPH/WELLINGTON } \\
\hline $\begin{array}{l}\text { Niagara Region Distress Centre (St. Catherines, } \\
\text { Ontario) }\end{array}$ & $\begin{array}{l}\text { mental health; social change; emergency com- } \\
\text { municaton }\end{array}$ \\
\hline $\begin{array}{l}\text { *Oshweken School - Creative Encounters (Osh- } \\
\text { wekan, Ontario) }\end{array}$ & $\begin{array}{l}\text { Youth (aboriginal youth); science leadership/ } \\
\text { voice; music; health }\end{array}$ \\
\hline $\begin{array}{l}\text { York Region High Schools - Exploration Career } \\
\text { Choice (Greater Toronto Area, Ontario) }\end{array}$ & youth career development; leadership/voice \\
\hline
\end{tabular}

* Indicates a team project.

It was found that the individual or team CSL projects were not distinctly different with respect to the topics addressed in CSL. The topics also did not differ greatly with respect to those addressed in formal organizations (NGOs or schools) versus those within informal neighbourhood or special interest groups. What did become apparent was the importance within team projects of a student who had a previous connection to the local community organization which led to facilitating initial communication and trust relations between the team and the local organization. The reflections of students involved in team projects were generally positive and typically, team efforts were the most extensive in terms of the depth and number of activities within the learning process as well as the scope and scale of materials produced.

The more personal and in-depth critique noted within the reflective journals as well as the final project documentation was found in individual projects. In this respect, individual students accepted their responsibility as social change agents, struggling to move ahead as soon as possible, and as in depth as possible, with the community organizations. In two of these cases, the student exited the project before the end of the course. In one of those cases, the student found the conflict within a small town over the closure of the local pulp and paper mill impossible to navigate as a communicator without creating greater problems. In the other one, the student had taken on too wide an activity, and refined the work to focus on activity involving one school rather than a service to the entire school region.

There was one case in which the student actively resisted accepting responsibility for not fulfilling the expectations of community members. This was in part due to the student's own agenda to promote the activity (a sport in which the student was quite an expert) over the process of discussing the relevance of the activity within the community. The 'learning contract' did not match the eventual outcome of the project. The student reflected later that his eagerness to promote the activity "put the solution before the problem (and that) he learned to ask not tell."

Overall, individual and team projects were found to reinforce the progressive knowledge, attitudes and skills anticipated by CSL. Students were able to reflect on their own individual role in social change, engage in participatory communication and discuss ideals relevant to peace, human rights and democratic development within their local context. Surprisingly, rarely did students document their learning as influencing the community organization's learning - rather, it was almost always the other way around. The students reflected again and again that the community organization and its members were valued educators for them as university students. 
From the vantage point of the community organizations, CSL led to innovative learning materials where such product did not exist and could not exist without student involvement. The design of learning objects (e.g. curriculum, videos, participatory workshops, etc.) and assistance with process development were especially valued by the community organizations. At the same time, community organizations often expressed a reluctance to comment on situations in which students were less effective in CSL or their learning materials and process were not useful to the organization. In some cases, this reluctance was due to a substantial turnover in the volunteers, leaders and staff within the community organizations. As time went by, it was harder to locate respondents within the local organizations who could comment on their interactions with students. In two situations where community actors felt students were unable to participate fully within the activities the reactions from the community organization indicated that it was the organization's shortcomings of time and not the limitations or lack of responsibility by the students. Some students did confirm that the lack of time within the CSL process limited the achievement of their learning objectives, but several of them demonstrated their willingness by continuing their interaction with the community organization after the course ended, or as long as they were located in the local area.

During follow-up, it was apparent that community organizations were eager to explore future opportunities to engage with students in CSL. The requests collected indicated a demand not only for students, but for participatory, social change oriented activity, including by well-established service NGOs such as local health centers and the YWCA/ YMCA. We were surprised by the breadth of activity that students sought out and then organized for themselves. Neither did we expect community organizations to be so willing to enable student learning, in part due to their immense resource constraints. Concerns about service learning activities going wrong and potentially harming the community organization and its members in some way were not justified. No doubt, new conceptualizations of CSL are needed to avoid assumptions that students will not conflict overtly with their collaborating organizations. This can happen, according to reflections among the students who have experienced the approach. There are also less dramatic situations in which community or student malaise can surface and affect the process of CSL. These situations moved from 'mentoring to tormenting' in that in more than a few cases, there was a need for intervention aimed at getting to the real reasons behind the student's lack of satisfaction with their project. This took immense time when such situations did arise, and thankfully in our experience, they were rare. After these past years of using CSL, undergraduate students are more likely to err on the side of cautiousness, if not respect and admiration, in their interactions with local communities.

Overall, our expectations regarding CSL as a method for enabling students to learn about the importance of non-formal education and communication process outside the confines of the formal classroom were generally met. Findings were positive with respect to accomplishing short-term benefits. The longer-term benefits are still uncertain, in part because contact with graduates is needed to track the potential impact of CSL experiences in their lives, careers and social activism.

Our major concerns relate regarding CSL relate primarily to the lack of participatory communication among students within the classroom (face to face or on discussion boards within distance education classes). Sharing experiences in the CSL process was easier said than done. Students could be harsh with one another - criticizing for instance, 
a peer's perspective on social change that was either too ambitious, or not sufficiently ambitious. The CSL approach is challenged by different individuals having sufficient time to share points of view and experiences in a non-judgemental manner. Open discussion boards, in our experience, are not conducive to peer-to-peer interaction in CSL. This is a separation of critical thinking and discussion that criticizes others - a communicative capacity that may require, in future, a specific tool for analysis and learning.

After the first year of using CSL, a decisive shift from the teacher identifying community organizations for students to contact to encouraging students to contact organizations of their own inclination. This aspect of CSL allowed students to take responsibility for their 'learning contract' with local community organizations. However, each year it also did raise a substantial debate within the class about what can be considered a "community organization", and whether a special interest group existing without a broader community mandate can be considered part of a wider social change and development process. In the end, we think it was an accomplishment to bring students to the heart of contested social identities and heterogeneity within communities. Such discussions allowed students to deconstruct the notion of social structure which is intrinsic to the idea of social agency. Students were also questioning power relations and the role of formal institutions within processes of local change and development. Perhaps it is these aspects of the CSL approach that we hope students could continue to wrestle with in their future communicative relationships and careers.

\section{Concluding Remarks}

Using community service learning to teach and learn non-formally within local communities enables a level of collective inquiry and individual reflection based outside the classroom that is often missing in higher education. These processes are tremendously important to mobilizing global communication because students will find many lessons within their local communities and relate them to broader peace, social justice and development issues. In our sense-making of CSL we hope that the direction of future work will involve students leading this process, perhaps best as individuals, but also effectively as teams (Derwin 2003). The peer interaction among experiential learners is important and we recommend that new work in CSL might look at ways in which social media can support non-judgmental peer exchange and collaboration among students involved in CSL.

For students from any discipline who seek careers in community development or international development the opportunities of CSL make the global tangible locally. There is also the potential for analysis of the student's self concept and strengthening communication knowledge, attitudes and skills. While non-formal education such as CSL is not going to replace formal educational systems, it can offer experiential learning in fields such as communication process where the local actor perspective and the experience of dialogical processes are crucial. One future task could be to network communication-related CSL more effectively within and among our institutions to develop the approach and address its challenges. Engaging globally on CSL issues and shared experiences may also enable us to be more effective communicators for change and development locally. 


\section{Notes}

1. Helen Hambly Odame is Associate Professor at the Capacity Development \& Extension program in the School of Environmental Design and Rural Development, University of Guelph, Canada (e-mail: hhambly@uoguelph.ca). Natalie Oram is currently a MSc. candidate at Wageningen University, the Netherlands (e-mail: natalieoram@gmail.com).

2. For literature on communication for social change and development see Waisbord (2001) and GumucioDagron \& Tufte (2006).

3. Knowledge is retained information concerning facts, concepts, and relationships. Attitudes consist of feelings or statements for or against certain issues; they reflect the predisposition of individuals to view their jobs, other people, and the work in a certain way, and they are reflected in people's behavior, for example, in terms of responsiveness, flexibility, self-confidence, adaptability, tact, etc. Skills are the abilities to do things effectively. This is the application of knowledge and personal aptitude and attitudes in work situations. These are known as "soft skills" (or humanistic skills) including contacting and talking to people that you have not previously met, participating or conducting meetings, giving and receiving feedback, listening skills and so on. "Hard skills" are more typically based on applied knowledge and psychomotor abilities.

4. The University of Guelph offers five elective undergraduate courses in communication process (http:// www.communicationprocess.ca) We also offer a Masters of Science degree in Capacity Development and Extension which include themes such as: 1) adult learning and development, and 2) communication for development (http://sedrd.uoguelph.ca/RES/programmes.html).

5. Non-formal learning is not necessarily provided by a formal educational or training institution. It is an intentional and structured learning experience that occurs outside the walls of the classroom. There may be a teacher and there may be some degree of certification or recognition of completion. In other words, learning is not random in non-formal education.

6. The University of Guelph has a program known as Student Life that promotes leadership and community engagement (http://studentlife.uoguelph.ca/lce/). In Canada, CSL was first developed in 1996 at St. Francis Xavier University in Nova Scotia. Universities using this approach convened in 2002 at the University of Guelph leading to the formation of the Canadian Association of Community Service Learning (CACSL).

7. Using a survey form, we obtained written feedback from seven of these community organizations on their perceptions of the CSL process and the longer-term outcomes of some of these projects. Some community organizations did not complete the survey but were followed up using direct visits, email or by telephone.

\section{References}

Canadian Alliance for Community Service Learning (CACSL) (2011) 'What is CSL?' CACSL Website. Retrieved from: http://www.communityservicelearning.ca/en/

Dervin, B. (2003) 'Audience as listener and learner, teacher and confidante: The sense-

making approach', in Dervin, B., Foreman-Wernet L., \& Launterbach, E. (eds.) Sense-making methodology reader: Selected writings of Brenda Dervin. (pp. 215-231). Cresskill, NJ: Hampton Press, Inc.

Fenwick, T. (2000) 'Expanding conceptions of experiential learning: A review of five contemporary perspectives', Adult Education Quarterly 50(4): 243-272.

Freire, P. (2007) Pedagogy of the Oppressed. New York/London: Continuum.

Gumucio-Dagron, A., \& Tufte, T. (eds.) (2006) Communication for social change anthology: Historical and contemporary readings. New Jersey: Communication for Social Change Consortium.

Hayes, E. \& King, C. (2006) Community service-learning in Canada: A scan of the field. CACSL Website. Retrieved from http://www.communityservicelearning.ca/en/documents/ScanofCSLinCanada_002.pdf

Hemer, O. \& Tufte T. (eds.) (2005) Media \& Glocal Change. Rethinking Communication

for Development. Argentina, Buenos Aires: CLACSO.

Kolb, D.A. (1984) Experiential learning: Experience as the source of learning and development. New Jersey: Prentice-Hall, Inc.

Kolb, D.A. \& Fry R. (1975) 'Toward an applied theory of experiential learning', in Theories of group processes, Cooper, C. (ed.), (pp. 33-58). London, UK: John Wiley \& Sons.

Newson J. \& Polster, C. (eds.) (2010) Academic callings: The university we have had, now have, and could have. Toronto, ON: Canadian Scholars' Press Inc.

Trenholm, S., Jensen, A. \& Hambly, H. (2010) Interpersonal Communication. A Guided Tour for Canadians. Don Mills, Ontario: Oxford University Press. 
Vella, J. (2002) Learning to Listen, Learning to Teach: The Power of Dialogue in Educating Adults. $2^{\text {nd }}$ Edition. San Francisco, CA: Jossey-Bass.

Waisbord, S. (2001) Family Tree of Theories, Methodologies and Strategies in Development Communication. New York: The Rockefeller Foundation. Retrieved from http:/www.comminit.com/?q=global/node/1547

Wolfson, L. \& Willinsky, J. (1998) 'What service learning can learn from situated Learning', Michigan Journal of Community Service Learning, 5:22-31. 